\title{
Design a New Pressure Regulating Valve for Fuel Injection Pump of Diesel Engine
}

\author{
Aishwarya Krishnat Jadhav ${ }^{(1)}$, Dr. S.G. Joshi( ${ }^{(2)}$, Prof. P.D. Maskar ${ }^{(3)}$, Mr. Sandip V. Patil ${ }^{(4)}$ \\ (1) M. Tech Final Year Student, Department of Mechanical Engineering, Walchand College of Engineering, Sangli, India. \\ ${ }^{(2,3)}$ Project Guide and Co-guide, Department of Mechanical Engineering, Walchand College of Engineering, Sangli, India. \\ ${ }^{(4)}$ Company Project Guide, Cummins Fuel Systems, Cummins Technical Centre India, Pune.
}

\begin{abstract}
Diesel fuel is a primary source of energy for Diesel engines. Fuel System consisting of a Fuel Injection Pump, Common rail and Injector provides a pressurized, atomized and metered quantity of fuel to the cylinders of Diesel Engine. Fuel Injection Pump is a key component in a Fuel System. It consists of a Low-Pressure Pump (LPP) and High-Pressure Pump (HPP). For proper and safe operation of a fuel pump, fuel pressure inside a pump should be regulated at safe levels. Pressure Regulating Valve (PRV) is a type of control valve which serves a purpose of regulating a constant pressure within fuel pump providing a safety for all key components of Fuel System. In this paper, design of a new Pressure Regulating Valve is carried out. The entire product development process is followed for the design of PRV. It consists of concept generation, selection of the most potential concept followed by CFD Analysis and Testing of a manufactured prototype of PRV on a performance test rig to validate results.
\end{abstract}

Keywords- Fuel System, Fuel Injection Pump, Pressure Regulating Valve (PRV), Low Pressure Pump (LPP), Pugh Matrix, Computational Fluid Dynamics (CFD) Analysis.

\section{INTRODUCTION}

Recent technologies in Diesel engines are driving a requirement for better and precise Fuel System with higher pressure requirements. Hence there is need of safety measures which prevent fuel system parts from any damage. Cummins in India designs, manufactures, assembles and services Diesel Engines and related technologies.

Figure.1.1 shows a schematic flowchart which indicates the important components in the common rail fuel system used for diesel engine.

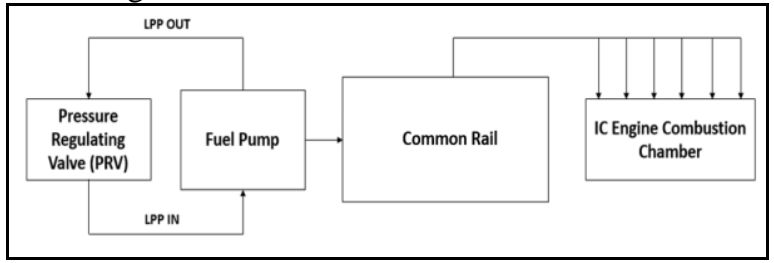

Fig. 1.1 Flowchart indicating fuel system components.

Key components of Fuel System include Low Pressure Pump (LPP), Pressure Regulating Valve (PRV), High Pressure Pump (HPP), Common Rail and Injectors. LPP is a positive displacement pump which creates suction at inlet and lifts fuel from tank via primary filter. Filter is used to prevent any type of debris entering a pump. PRV is placed in between LPP and HPP. It regulates pressure in the circuit before fuel enters in HPP. After entering a fuel in HPP, it gets pressurized during pumping event and driven to a common rail. Further it is injected into engine cylinder with the help of injectors.

This paper is more concerned about a design of PRV and its working. It is either incorporated in LPP housing or HPP housing.

A typical spring loaded PRV is shown in figure 1.2. It consists of a moving plunger, spring and a spring adjustment screw for preload setting. The symbolic representation of PRV used in hydraulic circuit is also shown in figure 1.2. It is spring loaded normally closed valve. In normal operating condition, plunger rests at its seat and do not allow any flow of fuel through it. When a pressure in a circuit i.e., at LPP outlet exceeds a preset value of, plunger lifts from its seat and allows a fuel flow through it. This fuel is bypassed to either tank or recirculated back to LPP inlet.[8]

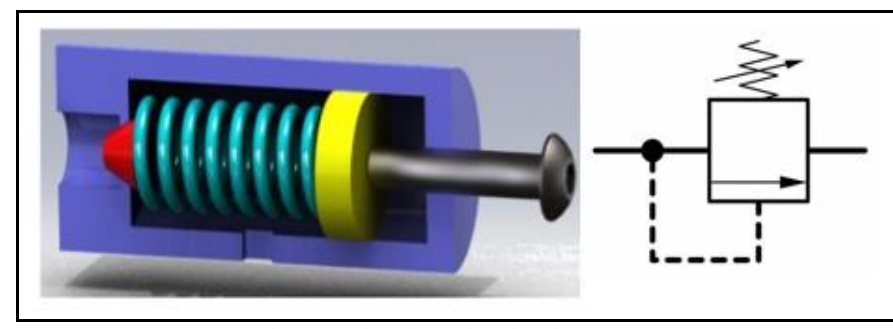

Fig. 1.2 Simple spring loaded PRV

A typical Characteristic curve for pressure regulating valve is shown in fig. 1.3. It is a graph of pressure vs flow through a PRV.

With the help of spring, required value of pressure is maintained. This pressure is called pre-set pressure. When pressure increases beyond this value then plunger lifts from its seat and pressure is relieved. After certain time, there is constant pressure across PRV and this pressure is called as regulated pressure.

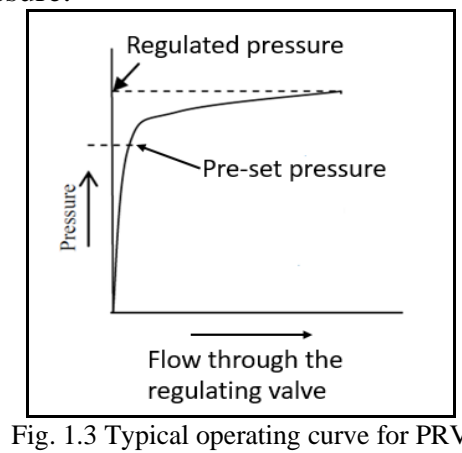

Pressure controls are mainly used to perform the following system functions: 
1. Limiting the maximum pressure in the system to a safe level.

2. To reduce / decrease the pressure in some parts of the circuit.

3. Reduce excessive pressure from the system.

4. Assisting the sequential operation of actuators in circuits with pressure control.

5. Any other pressure-related function due to pressure control.

6. Reducing or lowering the pressure level from the main circuit to the low pressure in the sub-circuit.

Design of PRV is based on the factors which are enlisted below:

a. Inlet pressure to PRV

b. Maximum inlet pressure

c. Pressure to be regulated

d. Inlet flow to PRV

e. Outlet flow from PRV

f. Flow to be by-passed to drain

g. Flow area for fluid through PRV

h. Flow area for bypassing the fuel

i. Gear pump (LPP) rated flow and pressure at various speeds.

\section{CONCEPT GENERATION FOR DESIGN OF PRV}

The first step in design of a PRV was concept generation based on various principles of operation. It includes Mechanical, Electrical, Magnetic, use of smart materials like Shape memory alloys, Magnetorheological Fluids etc. The schematic and working of the concepts generated for PRV are explained below:

\section{A. Magnetic solenoid operated PRV:}

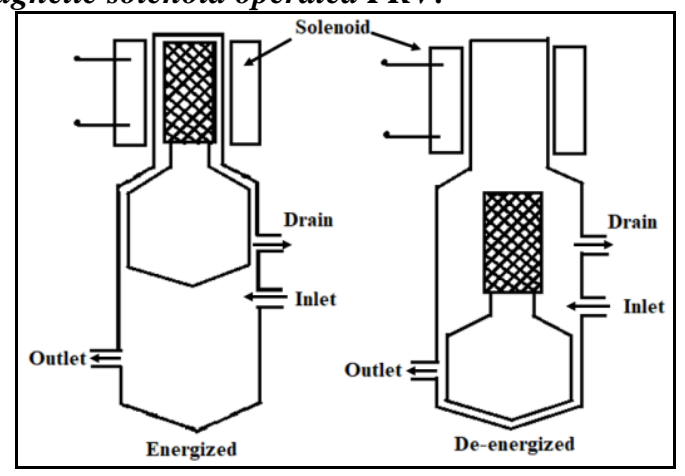

Fig. 2.1 Schematic of magnetic solenoid operated PRV

The concept shown in fig. 2.1 consists of a magnet connected to spool and a coil wound around the outer surface of the valve body. It consists of three ports viz. inlet, outlet and drain as shown in the figure. It is electronically operated PRV. It needs continuous supply of electric current for its working. Fig.2.1 shows the position of spool when the circuit is energized. The spool containing magnet is held at the upper position closing the drain port. The fuel enters the valve trough inlet and comes out through outlet port without bypassing to the drain port. When there is pressure rise in the circuit the electric supply to the coil will be shut off and coil becomes de-energized which will move the spool downwards closing the outlet port. Now the fuel from inlet will go to the drain line and from there to the low pressure return line of the circuit. This position of spool will remain same until pressure in the circuit is regulated, after that again coil will be energized by supplying an electric current and spool will be lifted upwards opening the outlet port.

\section{B. Hydraulic Actuated Spool Valve:}

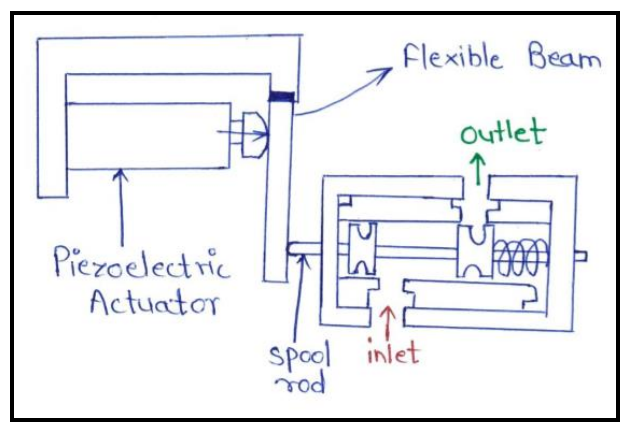

Fig. 2.2 Schematic of hydraulic actuated spool valve

The hydraulic actuated spool valve is controlled by using piezoelectric actuator. The schematic of the concept is shown in fig. 2.2. it consists of a piezoelectric actuator, a flexible beam, sliding spool, spring and a valve body with inlet and outlet ports. Here, the outlet port will be connected to drain line.

When the system pressure increases, the electric supply is given to the piezoelectric actuator. The piezoelectric actuator pushes the flexible beam towards right through a push rod. The spool resting on the surface of flexible beam which in turn is operated by the movement of piezoelectric actuator. As the spool is moved towards right side, outlet port will get open and the flow will be sent to drain. When the pressure in the circuit is at safe level, piezo-electric actuator will be deenergized, and the position of flexible beam will be vertical. The spring attached to the spool near outlet port will push back the spool to its original position i.e. towards left and outlet port will get closed.

\section{Magneto-rheological fluid (MRF) controlled PRV:}

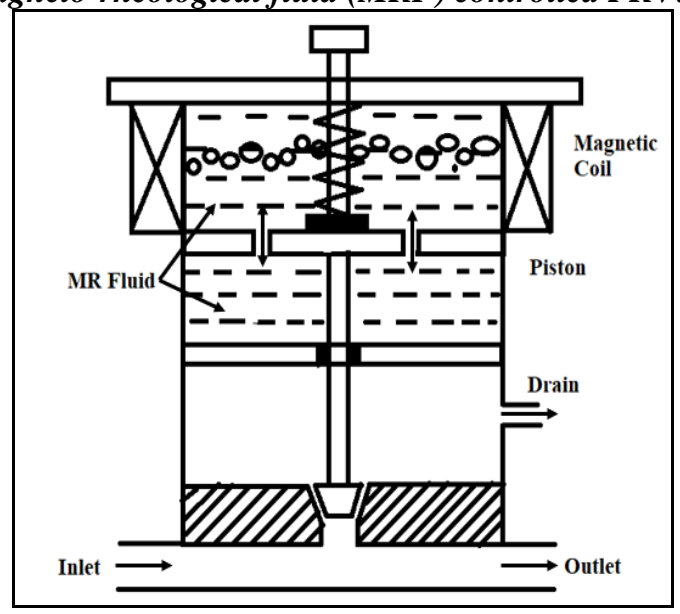

Fig. 2.3 Schematic of Magneto-rheological fluid control valve

The schematic of Magneto-rheological fluid controlled PRV is shown in figure 2.3. The working principle of this type of PRV is based on the property of change of viscosity of MR fluid by controlled passage of electric current through magneto-rheological fluid. As the current passes through the fluid, electric dipole moment is generated within the 
magnetic atoms present in the MR fluid due to which atoms get aligned and forms chain like structure. Due to this phenomenon, viscosity of fluid increases. This unique property of MR fluid can be used for actuation of pressure regulating valve. The concept shown in fig. 2.3 consists of a valve body, moving piston, MR fluid, spring, a magnetic coil with electric connections and a spool. The valve is normally closed. To maintain the spool position at its seat, continuous supply of electric current should be given to the magnetic coil. Due to this, the viscosity of MR fluid will increase which will constraint the flow of MR fluid through the holes provided on the piston to the upper portion of the piston and hence the spool will remain at its seat restricting the fuel flow at inlet of the valve. When pressure in the circuit increases beyond the set pressure, electric supply will be shut off and due to this viscosity of MR fluid will decrease which leads to the flow of MR fluid from holes on the piston to upward side. This upward motion of MR fluid results into lifting of spool from its seat and extra pressure fluid will flow to the drain line.

\section{By-Pass Fluid PRV:}

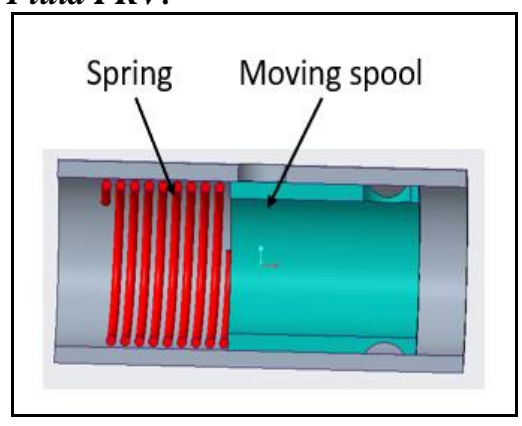

Fig.2.4 Schematic of By-Pass Fluid PRV

Bypass fluid PRV consists of a Valve body, spring, moving spool and a drain port as shown in fig. 2.4. The fluid flowing through this valve exerts force on the cross-sectional area of spool due to which it slides inside the valve body. On the other side of spool, spring is placed which limits pre-set pressure inside valve. Spring also helps in returning of spool back to its original position. The spool and the outer cylinder consist of holes. When these holes get align, it passes extra fuel to the drain reducing the pressure in flow line. As the extra flow is bypassed to the drain it is called as by-pass fluid PRV.

\section{E. PRV with Inductive Displacement Transducer:}

PRV with inductive displacement transducer consists of a spool with magnet attached at one end, spring, inductive displacement transducer with electric supply, drain port as shown in fig. 2.5. The gap between the spool and inductive displacement transducer is maintained by providing electric supply. Spring is provided for allowing the spool back to its original position. When the pressure in the circuit increases, the pressure gauge will measure the increase in the pressure and equivalent amount of current will be given to the inductive displacement transducer. Due to this, magnet will shift upwards lifting the spool from its seat and allowing the fuel to flow towards drain line.

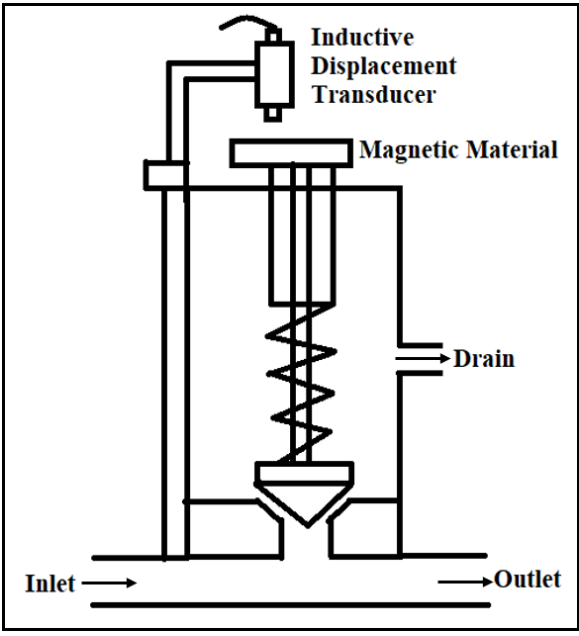

Fig. 2.5 Schematic of PRV with Inductive Displacement Transducer

\section{F. Shape Memory Alloy (SMA) Actuated PRV:}

Shape memory alloys have the unique property of changing its shape when temperature is increased and return to its original shape when heat is removed. This property of shape memory alloys is used for the actuation of valve. The main parts in SMA actuated PRV includes SMA wires wound around a frame like structure, frame connected to the spool, electric supply, heat source and a drain port as shown in fig.2.6. For maintaining spool at lower most position i.e. at seated position, continuous supply of electric current is given to the heat source which in turn generates heat and transfers it to the SMA wires. [6]

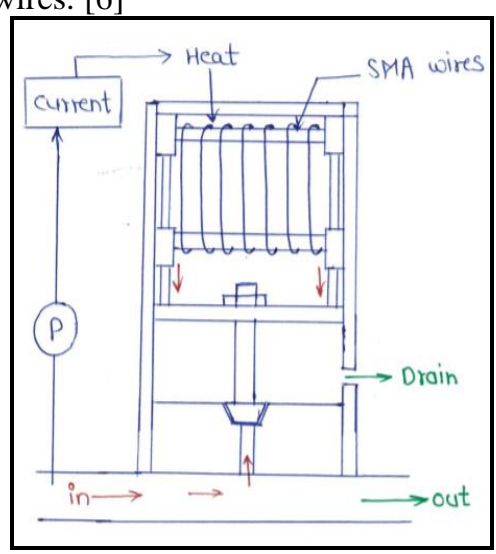

Fig. 2.6 Schematic of SMA Actuated PRV

Wire gets elongated and pushes the spool down closing the inlet port of the valve. When pressure increases above pre-set pressure, the electric current is shut off due to which SMA wires regain its original shape and spool lifts upward allowing the flow towards drain line.

\section{G. Cross Disc PRV:}

The construction of cross disc PRV is as shown in fig. 2.7. It consists of two discs placed inside a valve body. The crosssection of plate is shown in figure. The valve body contains internal groves along which the discs move. Spring is used for self-returning of discs at its original position. The pre-set pressure will be set by the spring. The disc 1 will have orientation as shown in fig. 2.7 and disc 2 will be placed by keeping some angle offset such that it overlaps the open portion of the previous disc. 


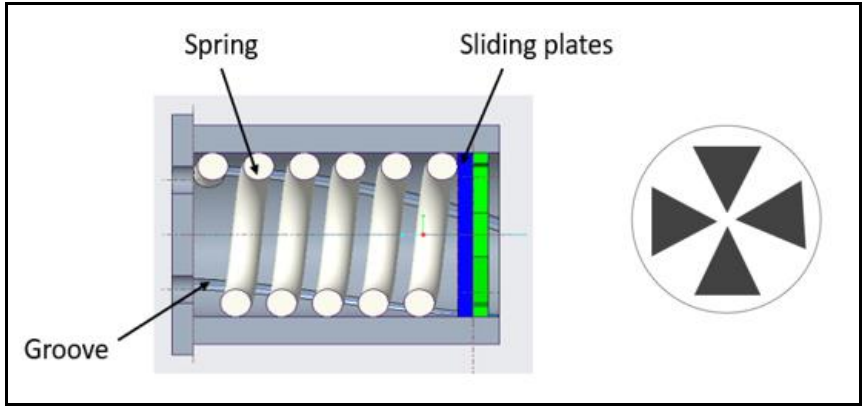

Fig. 2.7 Schematic of Cross Disc PRV

When the pressure increases, it will act on the cross-sectional area of discs and will turn the upper disc through the groove provided on the valve body. The motion of plate will be rotational as well as linear along the groove. When pressure drops to the pre-set value, spring force will push down the disc closing the flow to drain.

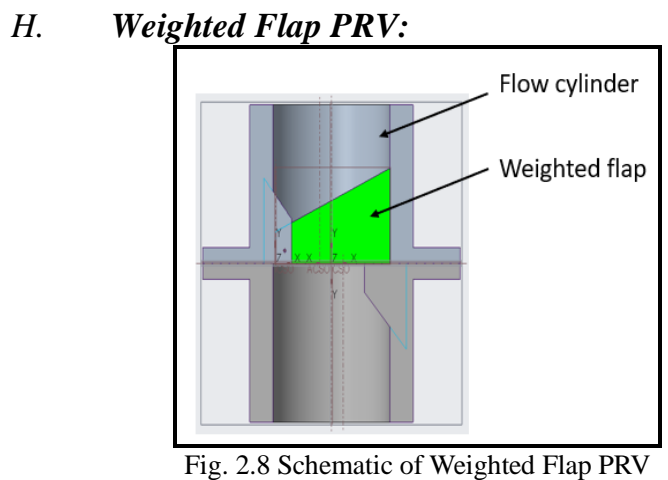

Weighted flap PRV works on a principle of gravitational force. It consists of a flap having weight equal to the pre-set pressure, a clamp and a valve body as shown in fig. 2.8. Flap is connected to a valve body with the help of a clamp at one end. The weight of flap is calculated such that the force due to gravity and the pre-set pressure required are balanced. When pressure in the system increases, flap will get open and the flow will be by-passed to return line. When the system pressure comes down to pre-set pressure, flap will be closed again.

\section{Spring Controlled Flap type PRV:}

Spring controlled flap type PRV is shown in fig.2.9. It consists of a flap with a spring attached to it which exerts pressure on it. The working principle of this type of PRV includes both spring force and a gravitational force.

When pressure increases beyond a pre-set pressure of a spring, flap gets open and the fuel goes to the outlet of the valve which further goes to the return line. When pressure is reduced, spring forces the flap back to its original position closing the flap. Due to this, flow to the outlet of valve is stopped.

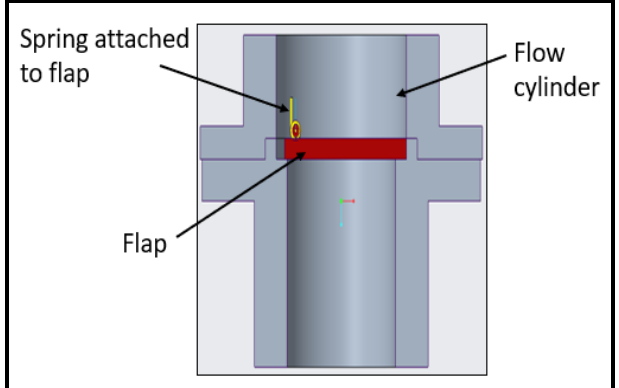

Fig. 2.9 Schematic of Spring Controlled Flap PRV

\section{J. Spool and Spring Controlled PRV:}

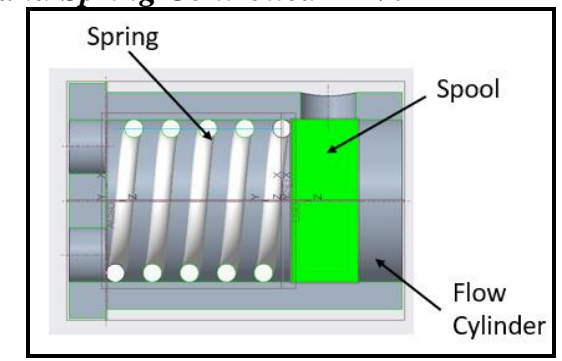

Fig. 2.10 Schematic of Spool and Spring Controlled PRV

Spool and spring controlled PRV consist of a piston type spool sliding inside a valve body. The position of spool will be decided based on the outlet port. The valve will be normally closed as shown in fig. 2.10. Spring is designed such that the outlet port of the valve is closed by the spool at pre-set pressure. When the pressure exceeds pre-set level, spool will move upwards and fuel will flow towards return line through outlet port. Holes in the top portion of the flow cylinder are provided to drain the fuel from piston and cylinder interface.

\section{K. Weighted Dual-Spool PRV:}

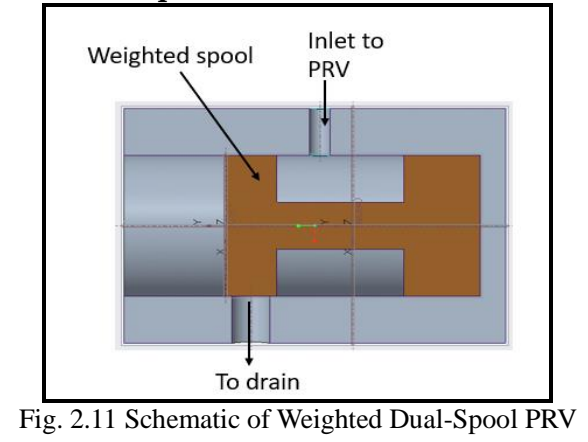

Weighted dual spool PRV consists of a spool having double piston like structure as shown in fig 2.11. This type of PRV works on the principle of gravity. Weight of the spool is calculated such that its movement is controlled according to the pressure difference. The distance between two pistons is maintained such that when pressure is increased the fuel enters from the inlet of the valve exerts force on the piston from right side. Due to this force, piston will move towards left and will open the outlet port. Once outlet port gets open, fuel from inlet port entering in the passage between two pistons will flow towards drain through outlet port. When pressure comes down to the pre-set value i.e. weight of spool, 
due to gravity it will again come downwards by closing outlet port.

\section{Cross hole PRV:}

Cross- hole type PRV is shown in fig. 2.12. It consists of outer valve body, a spring and a plunger with four crossholes. This type of PRV gives better sealing at the valve seat. Spring is used for pre-setting the desired pressure. When the pressure exceeds beyond the set pressure, plunger cross drills at upper end will get open in the outlet chamber of PRV. Due to the opening of these cross-drills, fuel will flow to the drain line. If there is further increase in the pressure, remaining two cross-drills at lower end will also get open in the outlet chamber and the excess pressure gets regulated by flow of fuel to drain line. When pressure gets decreased, spring forces the plunger back to its seat.

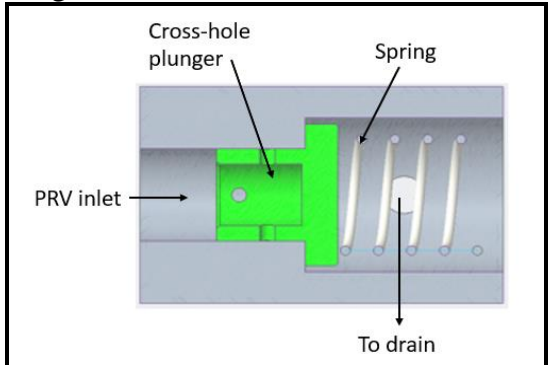

Fig. 2.12 Cross hole PRV

\section{Multi-hole plunger PRV:}

Multi-hole plunger PRV, fig. 2.13 consists of a plunger with multiple holes on its periphery for allowing flow of fuel to outlet port. The cross-section of plunger is shown in figure. Pre-setting is done with the help of spring. Extra projection on the plunger is provided for guiding a spring. Number of holes on plunger can be decided based on the flow area required to reduce the pressure to desired level.

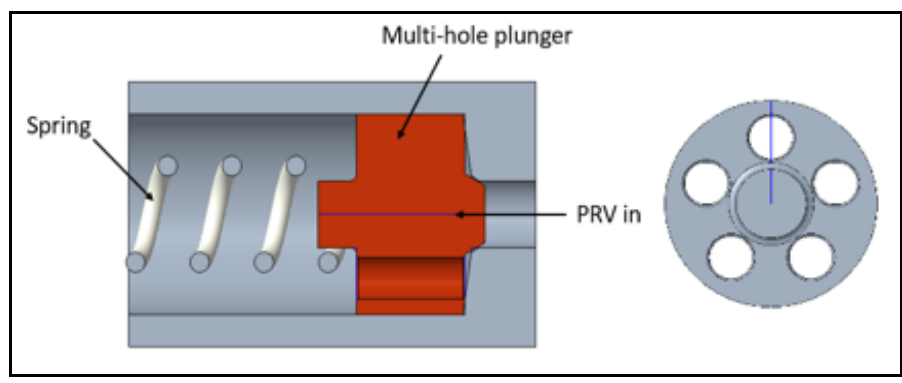

Fig. 2.13 Multi-hole plunger PRV

The valve is normally closed. When the pressure increases beyond pre-set pressure, plunger lifts from its seat and fuel flows through the holes provided on plunger to drain.

\section{CONCEPT SELECTION}

Concept selection is the process of evaluation concepts, comparing the relative strengths and weaknesses of the concepts and selecting one or more concepts in terms of customer needs and other criteria for further investigation, testing or development.

\section{A. Pugh matrix for evaluation of concepts:}

During concept selection, initially concepts are evaluated relative to a baseline product using the Pugh matrix. Pugh
Matrix is a type of Matrix Diagram that allows for the comparison of several design concepts leading ultimately to which best meets a set of criteria. The relative comparison is carried out for screening of concepts. For Pugh matrix used for the concept selection of PRV design, refer Table 1 in Appendix. (Page no. 12)

\section{B. Cause and Effect matrix for final selection of concept:}

In Pugh matrix selection process, detailed Quantitative comparisons are difficult to obtain and can be misleading, hence a rough one comparative rating system is used. After the process of rating, total score is calculated by adding all the positive and negative points. Pugh matrix only is not sufficient for the final concept selection as it gives only qualitative comparison results. Final score for two or more concepts might be equal. Hence it is difficult to finalize the single concept. To overcome this problem, C and E (Cause and Effect) matrix is used for finalizing the concept.

Typical C \& E matrix is shown in fig. 3.1. In this matrix, ratings from 1 to 10 are given for the concepts which got selected from Pugh matrix. One more advantage of this matrix is weightage is also given to the criteria, so we can get more accurate result. In C\&E Matrix, Customer Requirements are ranked by order of importance. Inputs and Outputs are rated by their impact. The Cause and Effect Matrix should determine what Key Process Input Variables should get the most attention.

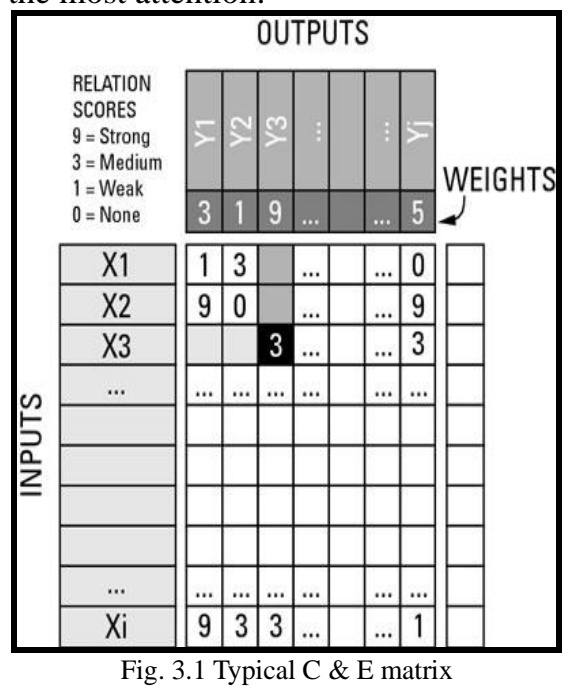

For cause and effect matrix a concept from Quality Function Deployment is been used i.e., for criteria selection weightage is given in terms of numbers 1,3 and 9. According to this technique, while evaluating one concept against other in order to determine which concept(s) should receive approval to proceed, a Ranked Scoring with Weights method allows for including the relative impact of each project on the criteria selected as important, with the criteria weighting permitting a prioritization of criteria one versus another. However, conventional 1-2-3 scoring can lead to ties, and very often projects can have very close scores. Using a 1-3-9 scoring system, borrowed from QFD, can "pop" projects to more clearly identify which projects to select while reducing the odds of an outright tie. For C \& E matrix used for final concept selection, refer table 2 in Appendix. After carrying 
out screening of concepts through C \& E matrix, a cross- hole Plunger PRV was selected for further design.

\section{DESIGN OF SELECTED CONCEPT OF PRV}

\section{A. Design of PRV:}

Design of a pressure regulating valve consists of the design of its plunger, force controlling element spring and the cap screw for holding this assembly in the pump housing. The factors considered for design are listed below:

(i) Design of a plunger is carried out based on the calculations including flow, pressure, flow area required for bypassing fuel and the spring force.

(ii)Spring design is done by considering factors like packaging space, desired spring stiffness, maximum operating load on the spring.

(iii) Cap screw design is carried out based on the axial forces acting, leakage considerations, friction torque required to tighten the screw according to ISO standards.

\section{B. Problem Definition:}

To design a Pressure Regulating valve that should regulate pressure of 10 bar in the circuit. The valve should open at a pressure of 10 bar. It should close when a pressure drops below 10 bar. Given that the maximum pressure that can be developed in the low-pressure pump is approximately 13 bar.

\section{Packaging of PRV in pump housing:}

Packaging of the pressure regulating valve in the pump housing is one of the important considerations. According to the pump housing architecture we identified two positions where PRV can be packaged as follows:

1) Front side of the housing:

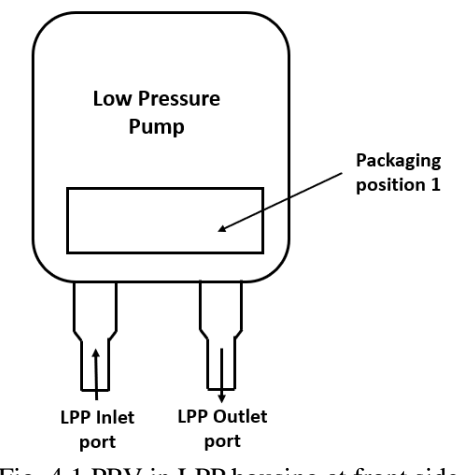

Fig. 4.1 PRV in LPP housing at front side.

The position for packaging of PRV is shown in fig. 4.1. The Low-pressure pump inlet and outlet are at left side and right side respectively when seen from the front. At this position, PRV will be placed horizontally with plunger on the right side, spring in the middle and cap screw at left side.

\section{2) Outlet port of LPP:}

The second position identified was in the outlet port of Lowpressure pump. Fig. 4.2 shows the schematics of the position of PRV. In this case, the PRV will be held in the housing in vertical position. With plunger at upper position, spring in the middle and the cap screw at bottom position.

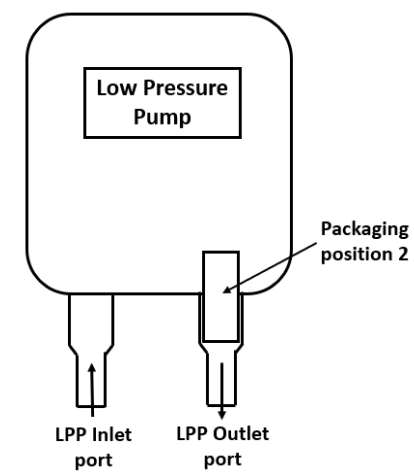

Fig. 4.2 PRV in housing at outlet port of LPP

\section{Selection of optimum housing thickness:}

PRV packaging position was finalized at the front of housing (Fig. 4.1) considering ease of manufacturing and assembly. This needs extra pocket for PRV packaging in the housing. Calculation of the required thickness of this pocket in the housing is done by considering the internal bore in the housing as pressure vessels. Pressure vessels are mainly classified as thin pressure vessels $(\mathrm{d} / \mathrm{t}>10)$ and thick pressure vessels $(\mathrm{d} / \mathrm{t}<10)$. For the housing thickness calculation, thick cylinder theory is considered. Lame's Equation is used for design of a thick cylinder when the material of the cylinder is brittle such as cast iron or cast steel. Three primary mechanical stresses considered in the design of thick cylinders. Then the maximum principal stress is equated to permissible stress for a material.

1. Hoop Stress/ Tangential stress $\left(\sigma_{\mathrm{h}}\right)$

2. Radial Stress $\left(\sigma_{\mathrm{r}}\right)$

3. Axial Stress/ Longitudinal Stress $\left(\sigma_{\mathrm{a}}\right)$

Hoop Stress, $\sigma_{\mathrm{h}}=\frac{P_{i}\left(D_{o}^{2}+D_{i}^{2}\right)}{\left(D_{o}{ }^{2}-D_{i}^{2}\right)}$,

Radial Stress, $\sigma_{\mathrm{r}=}-P_{i}$ and

Axial Stress, $\sigma_{\mathrm{a}}=\frac{P_{i} D_{i}{ }^{2}}{\left(D_{o}^{2}-D_{i}^{2}\right)}$

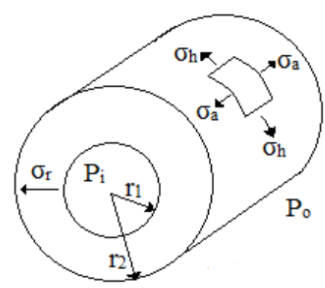

Fig. 4.3 stresses induced in the thick cylinder for a cylindrical object

The stresses acting on thick cylinder are shown in fig.4.3.

$\therefore \sigma_{\mathrm{h}}>\sigma_{\mathrm{a}}>\sigma_{\mathrm{r} \text { and }}$ hence, $\sigma_{\mathrm{h}}$ is the criterion of design.

$\frac{\Sigma_{h}}{P_{i}}=\frac{\left(D_{o}{ }^{2}+D_{i}^{2}\right)}{\left(D_{o}{ }^{2}-D_{i}^{2}\right)}$

$\frac{\sigma_{h}+P_{i}}{\sigma_{h}-P_{i}}=\frac{\left(D_{o}{ }^{2}+D_{i}{ }^{2}\right)+\left(D_{o}{ }^{2}-D_{i}{ }^{2}\right)}{\left(D_{o}{ }^{2}+D_{i}{ }^{2}\right)-\left(D_{o}{ }^{2}-D_{i}{ }^{2}\right)}$

$\frac{\sigma_{h}+P_{i}}{\sigma_{h}-P_{i}}=\frac{D_{o}{ }^{2}}{D_{i}{ }^{2}}$

$\frac{D_{o}}{D_{i}}=\sqrt{\frac{\sigma_{h}+P_{i}}{\sigma_{h}-P_{i}}}$ 
Substituting $\left(D_{o}=D_{i}+2 t\right)$ in above equation,

$\frac{D_{i}+2 t}{D_{i}}=\sqrt{\frac{\sigma_{h}+P_{i}}{\sigma_{h}-P_{i}}}$

$1+2\left(\frac{t}{D_{i}}\right)=\sqrt{\frac{\sigma_{h}+P_{i}}{\sigma_{h}-P_{i}}}$

$t=\frac{D_{i}}{2}\left[\sqrt{\frac{\sigma_{h}+P_{i}}{\sigma_{h}-P_{i}}}-1\right] \quad \ldots$ (Lame's Equation $)$

Where,

$\sigma_{h}=\frac{S_{u t}}{(f s)}$

The material used for housing is gray cast iron ASTM A48. The material property required for the calculation of thickness is ultimate tensile strength, $S_{u t}=200 \mathrm{~N} / \mathrm{mm}^{2}$.

Considering factor of safety $(f s)=5$, Putting these values in Lame's Equation,

$\sigma_{h}=\frac{200}{5}=40 \mathrm{MPa}$

$t=\frac{14}{2}\left[\sqrt{\frac{40+15}{40-15}}-1\right]$

$\mathrm{t}=4.28 \mathrm{~mm}$.

Hence, thickness of $4.5 \mathrm{~mm}$ was decided considering the factors such as engine vibrations transferred to the pump, vibrations due to road irregularities.

\section{E. Design of PRV Plunger:}

The concept shown in fig. 2.12, cross-hole PRV was selected for the detailed design of PRV. The design of the plunger includes sizing of the plunger considering packaging, desirable flow areas for bypassing the fuel and the forces acting on plunger. By considering all these aspects, the dimensions and material of plunger was finalized.

Fig. 4.4 shows an initial concept of PRV plunger and fig. 4.5 shows the schematics of the plunger after modifying some geometric features.

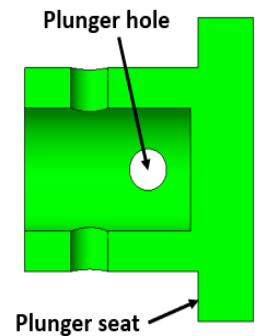

Fig. 4.4 Basic model of PRV Plunger

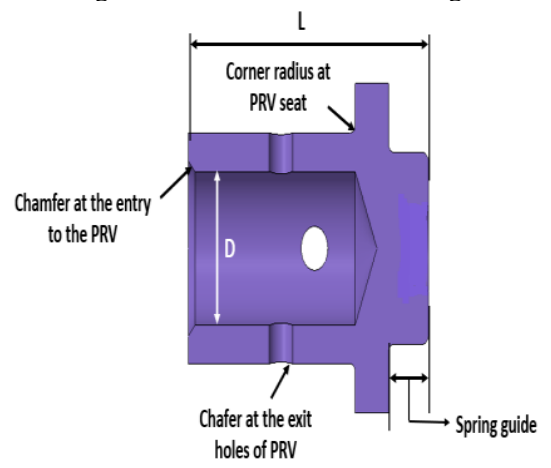

Fig. 4.5 Modified PRV Plunger
- The modified features are:

1. Length of the plunger should be more than two times of the diameter. i.e. $\mathrm{L}>2 \mathrm{D}$. when plunger slides within its stroke length, there are chances that it may get tilted and stuck. To overcome this problem, it is recommended to keep the length of the plunger greater than two times the diameter.

2. Chamfers are provided at the exit of the PRV holes to ensure laminar flow of fuel from it and to reduce turbulence at the edge of the holes. Also, the sharp edges can get eroded due to long term applications. To avoid all these possible issues, edge chamfers are provided.

3. Fillet at the corner of the plunger seat is provided to eliminate the contact between the plunger seat corner and the sharp edges at the corner of the pump housing.

4. The spring guide is provided at the upper portion of the plunger as shown in fig. 4.5. Compression springs tend to buckle. When the spring is compressed due to the effect of axial loading, below a critical length some springs tend to bend in the lateral direction instead of continuing to decrease in the direction of the applied load. This is called as buckling of springs. To avoid buckling phenomenon in the springs it is guided at the ends. The length of the guide is decided based on the free length of the spring and the mean coil diameter.

5. Fillet at the inlet of the PRV is provided to reduce turbulence in the flow path of the fuel due to the sudden changes in the cross-sectional area.

\section{F. Spring Stiffness Calculation:}

Based on the packaging and the desired spring properties, one of the combinations of spring wire diameter and mean coil diameter was selected. While calculating the spring stiffness, the material considered for spring was stainless steel with $\mathrm{G}=$ $76 \mathrm{GPa}$.

Figure 4.6 shows Combinations of various stiffness of spring with varying wire diameter and mean coil diameter considered for design.

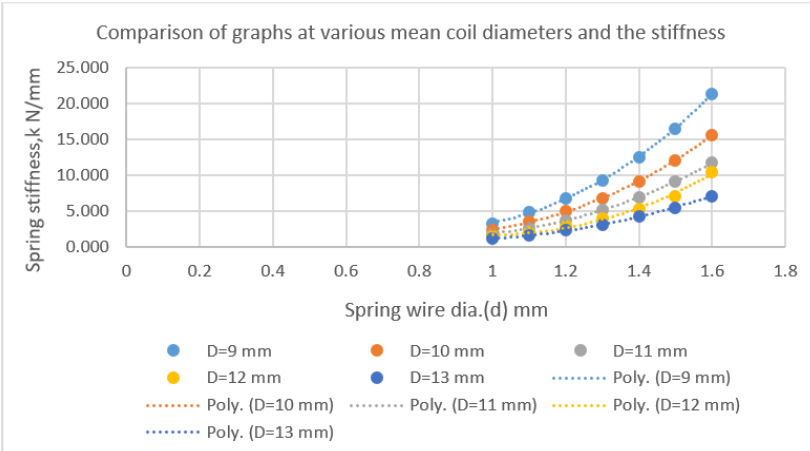

Fig. 4.6 Comparison of springs of different wire diameter and mean coil diameter

Comparing these combinations of spring with available packaging space, forces acting on plunger, a spring with stiffness $10.5 \mathrm{~N} / \mathrm{mm}$ was selected. 
V. CFD ANALYSIS OF SELECTED CONCEPT OF PRV

\section{A. PRV assembly given for CFD analysis based on Preliminary Calculations:}

The next step in the design of a new pressure regulating valve is CFD analysis. Preliminary force calculations on the PRV plunger were considered for the assembly of PRV components. The figure below shows Free body diagram for the PRV plunger. Two types of forces are acting on the plunger are as follows:

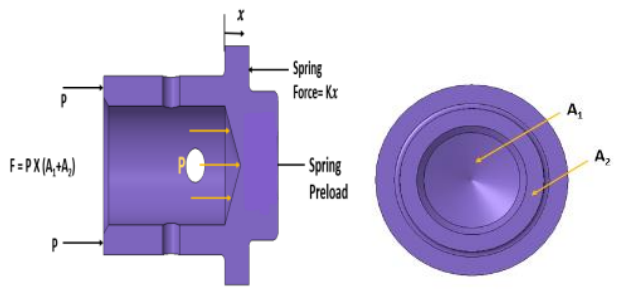

Fig. 5.1 Free Body Diagram of a PRV Plunger.

1. Pressure of fuel acting on the area $A_{1}$ and $A_{2}$

2. Spring force $(\mathrm{F}=\mathrm{k} x)$ acting opposite to the pressure of the fuel.

Table 5.1 shows a fuel pressure at LPP outlet and corresponding load being acted upon the plunger. The initial spring pre-load was considered as $20 \mathrm{~N}$ based on requirements of the pump. PRV should not get lifted from its seat at the pressure less than the cranking pressure, otherwise pump will not generate a required pressure.

The equilibrium equation used for preliminary force calculation on PRV plunger is,

$\boldsymbol{K} \boldsymbol{X} \boldsymbol{X}+\boldsymbol{F}_{\text {Preload }}=\boldsymbol{P} \boldsymbol{X} \boldsymbol{A}$

$$
\mathbf{F}_{\text {spring }}=\mathbf{F}_{\text {fuel Pressure }}
$$

Where,

$\mathrm{K}=$ Spring Stiffness N/mm

$x=$ Spring Deflection $\mathrm{mm}$.

$P=$ Pressure exerted by fuel from LPP Outlet on PRV Plunger.

$\mathrm{A}=$ Cross-section area of PRV plunger exposed to Fuel Pressure.

After balancing the forces on the PRV plunger, the location of cross-holes for bypassing the fuel were finalized. The diameter of the cross-drills will be finalized in the CFD simulation.

The table below shows a force acting on a PRV plunger due to fuel and the corresponding spring deflection.

\begin{tabular}{|c|c|c|c|c|}
\hline $\begin{array}{c}\text { Sr. } \\
\text { No. }\end{array}$ & $\begin{array}{c}\text { Pressure } \\
\text { (Bar) }\end{array}$ & Force (N) & $\begin{array}{c}\text { Deflection } \\
(\mathbf{m m})\end{array}$ & $\begin{array}{c}\text { Force acting on } \\
\text { plunger with 20 N } \\
\text { spring pre-load } \\
\text { (N) }\end{array}$ \\
\hline 1 & 7 & 60 & 3.82 & 40 \\
\hline 2 & 8 & 69.2 & 4.73 & 49.2 \\
\hline 3 & 9 & 77.85 & 5.53 & 57.85 \\
\hline 4 & 10 & 86.5 & 6.35 & 66.5 \\
\hline 5 & 11 & 95.15 & 7.18 & 75.15 \\
\hline 6 & 12 & 103.8 & 8.01 & 83.8 \\
\hline 7 & 13 & 112.45 & 8.83 & 92.45 \\
\hline
\end{tabular}

Table 5.1 Loads acting on PRV Plunger for different pressure values

\section{B. PRV Assembly:}

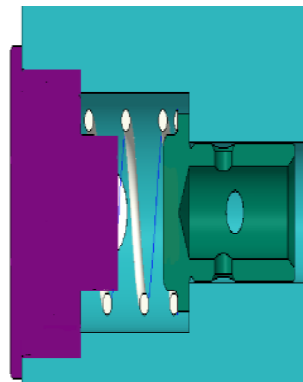

Fig. 5.2 PRV assembly in the housing

As shown in the figure. 5.2 above, PRV plunger, Spring and plug assembly is packaged into the pump housing. Spring is deflected initially to apply the required pre-load of $20 \mathrm{~N}$. The value of preload was considered based on the requirements of pump.

Fluid domain extracted for the CFD analysis is shown in the fig. 5.3. It includes the displacement/swept volume between the external gears, fuel lines from LPP outlet till filter and the LPP inlet.

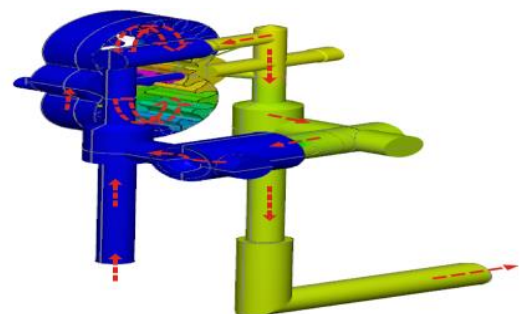

Fig. 5.3 Fluid domain and flow path for CFD analysis

Inputs required for the CFD analysis of PRV are:

a) CAD model of PRV, gear pump and the piping system.

b) Spring stiffness.

c) Flow areas of PRV for bypassing the fuel.

d) Low pressure pump performance table.

e) Clearances between the gear and housing.

From the CFD analysis of PRV, the important factors monitored were the flow areas considered are sufficient to bypass the required amount of fuel through PRV. Whether the spring stiffness is causing enough and controlled movement of PRV plunger.

\section{1) Average Pressure signature at Outlet}

As per the problem definition it was desired to regulate a pressure of 10 bar in the fuel line between LPP (Low Pressure Pump) to HPP (High Pressure Pump). The primary objective of PRV is to regulate the required pressure at LPP outlet.

\section{2) Simulation with Preliminary design calculations}

The graph shown below gives an idea about the regulated pressure at LPP outlet. On the ordinate, the regulated pressure is mentioned in bar and on abscissa we have the gear rotation in degrees from simulation. We get pressure fluctuations for corresponding gear rotation. When PRV plunger gets stabilized, the peak to peak pressure variation is reduced and we can consider the average value of pressure spike as a final value.

From the graph shown below we got the observations as follows: 
i. Graph shows two curves, one for the rated speed and the other for idle speed.

ii. PRV lifts from its seat at an approximate pressure of 6 bar. Then the cross drills open in the bypass line at 11.5 bar.

iii. The regulated pressure with the current combination of PRV Plunger, spring and plug was 11.5 bar.

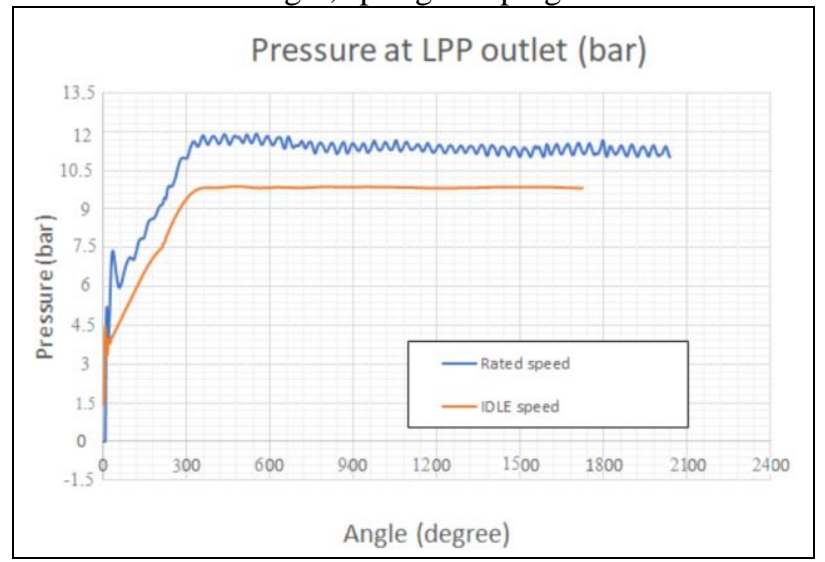

Graph 5.1 Variation of regulated pressure for rated and Idle pump speed

\section{3) Simulation with modified design parameters}

As a pressure of 10 bar is to be regulated, PRV simulation should be done by slightly varying the parameters like spring stiffness, spring preload. After that we performed the simulation by considering three combinations of Spring stiffness and preload.

In the first simulation we considered spring stiffness value of $10.5 \mathrm{~N} / \mathrm{mm}$ with preload of $20 \mathrm{~N}$. The value of regulated pressure coming is 11.5 bar which is slightly higher than the required value of 7 bar. So, it can be achieved by either reducing the preload or by reducing the spring stiffness so that more portion of the cross- drill will get opened in the bypass line and pressure can be further reduced to $10 \mathrm{bar}$. Considering these parameters, two more combinations of spring stiffness and corresponding preload were considered for CFD simulation.

Table 5.2 Combinations of stiffness and preload values considered foe CFD Analysis

\begin{tabular}{|c|c|c|}
\hline Sr. No. & Spring stiffness (N/mm) & $\begin{array}{c}\text { Spring Preload at installed } \\
\text { length }(\mathbf{N})\end{array}$ \\
\hline 1 & 10.5 & 20 \\
\hline 2 & 10.5 & 16 \\
\hline 3 & 10 & 20 \\
\hline
\end{tabular}

These three conditions are simulated on CFD and results were compared as shown in graph 5.2.

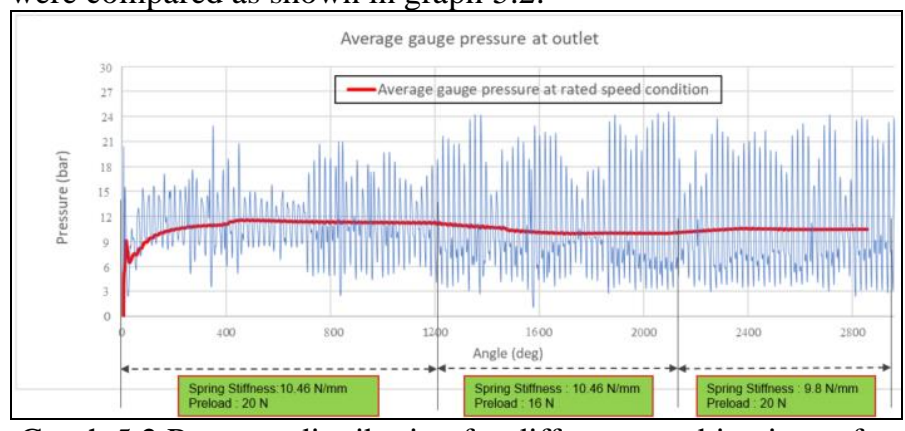

Graph 5.2 Pressure distribution for different combinations of spring stiffness and preload.
The graph shows pressure distribution at LPP outlet for three combinations of Spring stiffness and preload. Amongst these combinations, the third combination was most suitable from all perspectives. The table below shows the values of regulated flow and cranking pass-fail criteria for these combinations:

\begin{tabular}{|c|c|c|c|c|}
\hline $\begin{array}{c}\text { Sr. } \\
\text { No. }\end{array}$ & $\begin{array}{c}\text { Spring } \\
\text { stiffness } \\
\text { (N/mm) }\end{array}$ & $\begin{array}{c}\text { Spring Preload } \\
\text { at installed } \\
\text { length (N) }\end{array}$ & $\begin{array}{c}\text { Regulated } \\
\text { Pressure } \\
\text { (Bar) }\end{array}$ & $\begin{array}{c}\text { Cranking } \\
\text { Requirement }\end{array}$ \\
\hline 1 & 10.46 & 20 & 11.5 & Passed \\
\hline 2 & 10.46 & 16 & 10.5 & Failed \\
\hline 3 & 10 & $\mathbf{2 0}$ & 10 & Passed \\
\hline
\end{tabular}

Table 5.3 selection of spring stiffness using CFD results

For the new stiffness value, spring was again redesigned by changing spring parameters such as wire diameter and mean coil diameter.

\section{4) CFD Simulation for resonance:}

For passing resonance test, two criteria should be satisfied, and those are:

1. Maximum pressure spike should not go above the specified peak average pressure.

2. Peak to peak pressure should not go beyond a specified limit.

If these two conditions are satisfied, then the PRV is said to have passed resonance condition. If it fails, then by changing the flow areas and location of cross-holes the resonance can be eliminated.

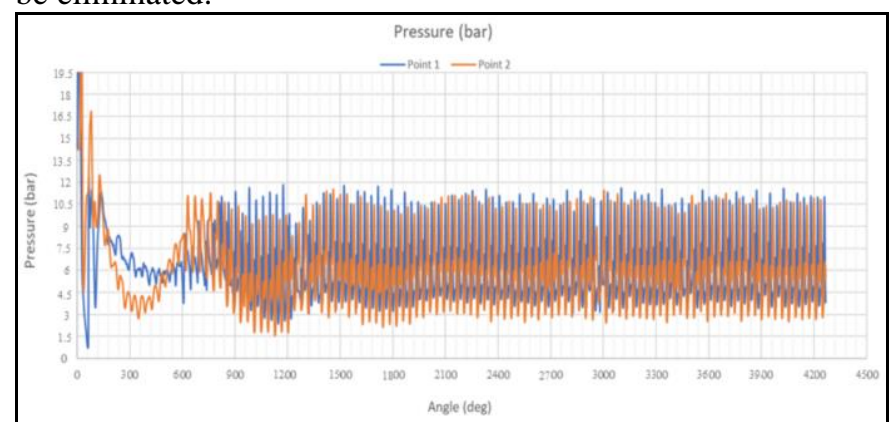

Graph 5.3 Pressure distribution Vs gear rotation angle for overspeed condition.

The graph 5.3 shows a pressure distribution at LPP outlet for resonance condition. It can be seen that pressure spikes are increased in overspeed condition than that of the rated speed. This increase in speed can cause a resonance condition causing maximum fluttering of a PRV plunger. If we compare the resonance pass/fail criteria listed above with this graph, then it can be concluded that the PRV design is passing the criteria and we can go further with this design for manufacturing.

\section{PERFORMANCE TESTING OF PRV PROTOTYPE}

After prototype Manufacturing of a PRV, testing was planned on a Low Pressure Pump performance rig in a lab. The primary objective of testing was to validate the results obtained from a CFD analysis. As the current LPP housing cannot accommodate PRV in it, different fixture was manufactured for this purpose. PRV was assembled in this fixture while testing and the connections were given to the pump. 


\section{A. Details of test setup:}

The figure 6.1 shows a test setup for PRV testing. It consists of a PRV holding fixture, Low Pressure Pump mounted between two cover plates and an adaptor used between LPP and a rig drive shaft. The connections of PRV fixture and Low-Pressure Pump were obtained with help of flexible hoses.

The test plan for PRV aims to check the outlet pressure and flow values at LPP outlet and check whwther these values meet the performance specifications of pump. The outputs obtained from CFD analysis were also compared with the test results for validation. As the LPP housing for PRV placement can't be modified, PRV was installed in the separate fixture designed as per requirements and PRV connections were given to the LPP.

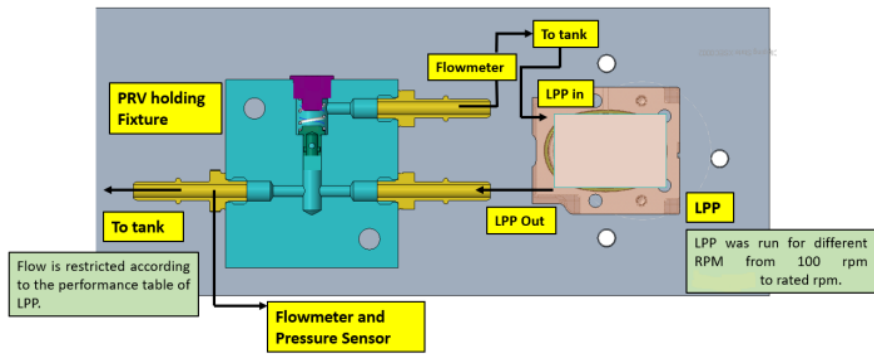

Fig. 6.1 Presure Regulating Valve Test Setup

The test plan for PRV aims to check the pressure at LPP outlet and check whwther these values meet the performance specifications of pump. The outputs obtained from CFD analysis were also compared with the test results for validation. As the LPP housing for PRV placement can't be modified, PRV was installed in the separate fixture designed as per requirements and PRV connections were given to the LPP. The connections were obtained using connecting hoses to the LPP and the fixture via end connectors. PRV holding fixture contains three ports. One connection is from LPP outlet to the inlet of fixture through which fuel is coming at PRV inlet. If the pressure value is greater than the preset pressure, then PRV lifts from its seat and the flow will go to tank via drain port. The third port at left side of fixture opens into the tank. At this port, flow is restricted to develop pressure near PRV. This flow value was recorded during testing and compared with the performance table.

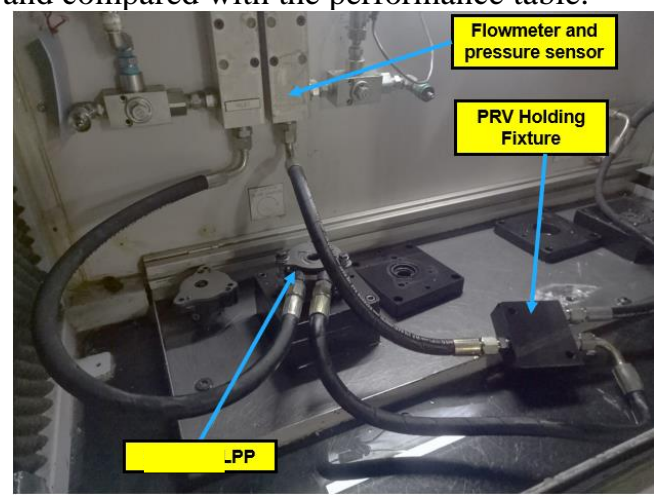

Fig. 6.2 Test setup on LPP Performance test rig.

Fig. 6.2 shows an actual test setup on a rig. Pump mounting, PRV holding fixture and necessary monitoring sensors such as flowmeter and pressure sensor are shown.
During testing LPP was run for different speeds starting from $100 \mathrm{rpm}$ till rated speed. Corresponding values of pressure and flow at outlet of PRV fixture were recorded. These values were compared with the performance table of pump and the values obtained from CFD analysis.

Table 6.1 Test results for a cross hole type PRV from Test Rig

\begin{tabular}{|c|c|c|c|}
\hline \multicolumn{4}{|c|}{ PRV Testing on Test Rig Data } \\
\hline Sr.No. & $\begin{array}{c}\text { Pump Speed } \\
\text { (rpm) }\end{array}$ & $\begin{array}{c}\text { Pump Outlet } \\
\text { Pressure (Bar) }\end{array}$ & $\begin{array}{c}\text { PRV Flow } \\
\text { (pph) }\end{array}$ \\
\hline 1 & 100 & 0.57 & 0 \\
\hline 2 & 300 & 1.34 & 0 \\
\hline 3 & 500 & 2.04 & 3.28 \\
\hline 4 & 800 & 2.78 & 23 \\
\hline 5 & 1000 & 3.43 & 31 \\
\hline 6 & 1200 & 3.97 & 10.5 \\
\hline 7 & 1500 & 4.47 & 20 \\
\hline 8 & 1800 & 5.29 & 33 \\
\hline 9 & 2000 & 6.35 & 55.55 \\
\hline 10 & 2200 & 7.43 & 15.2 \\
\hline 11 & 2500 & 8.56 & 17.5 \\
\hline 12 & 2700 & 9.68 & 17.8 \\
\hline 13 & 3000 & 10.17 & 19.76 \\
\hline 15 & 3300 & 10.05 & 31 \\
\hline 16 & 3600 & 10.21 & 42 \\
\hline 17 & 3800 & 9.89 & 49 \\
\hline 18 & 4000 & 10.23 & 57 \\
\hline & & & \\
\hline
\end{tabular}

From table 6.1, it is observed that for rated speed, pressure value is coming as 10.17 bar which is very close to the desired pressure value of $10 \mathrm{bar}$.

Below is the graph 6.1 which shows characteristic curve for PRV. It can be observed that after a preset value, pressure is not increasing further, and it is satisfying the requirements.

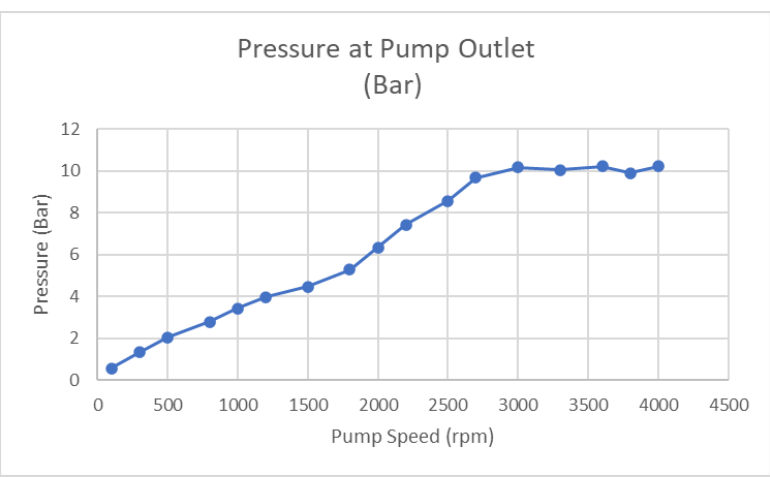

Graph 6.1 Pressure variation at Pump outlet

\section{CONCLUSION}

This paper includes concept generation of Pressure Regulating Valve (PRV), Selection of most potential concept, CFD analysis of selected concept and testing of manufactured prototype of PRV.

1. For concept selection, Pugh matrix and Cause and Effect matrices were used from which cross-hole PRV concept was selected.

2. After preliminary design calculations, CFD analysis was carried out. CFD analysis results shows that regulated pressure was within required range. Some modifications with spring stiffness and preload were done for more efficient working of PRV. 
3. After prototype manufacturing of PRV, testing was carried out at CFS Test lab. The results were compared with the CFD analysis observations. The pressure values obtained at outlet of pump were within required range.

\section{ACKNOWLEDGMENT}

The authors would like to thank Pump Development team, Structural and CFD team, CFS Lab, Cummins Technical Centre India, Pune for providing technical support for this work.

\section{REFERENCES}

[1] Andrea Vacca Divya Thiagarajana Stephanie Watkinsb, "On the lubrication performance of external gear pumps for aerospace fuel delivery applications", Journal of mechanical systems and signal processing, pp.659-676, 2019.

[2] Dazhuan Wua, Shiyang Lia, Peng Wua, "CFD simulation of flowpressure characteristics of a pressure control valve for automotive fuel supply system", Journal of Energy conversion and Management, pp.658-665, 2015 .

[3] William W. Ni, Steven Heitz, Daniel Bartholme and Michael Cass, "Compensation Force CFD Analysis of Pressure Regulating Valve Applied in FMU of Engine and System Controls", SAE International Journal, doi:10.4271/2011-01-2641.

[4] Binod Kumar Saha, Himadri Chatopadhyay, Pradipta Basu Mandal, Tapas Gangopadhyay, "Dynamic simulation of a pressure regulating and shut-off valve", Journal of Computers and Fluids, 101 (2014), pp.233-240.M. Young, The Technical Writer's Handbook. Mill Valley, CA: University Science, 1989.

[5] Constantin Opran, Mircea Pricop, Constantin Teodoru, "Researches on Design and Manufacturing of Innovative Double Gear Pumps", International Symposium on intelligent manufacturing and Automation, pp.475-481, 2015.
[6] Patent on "Shape Memory Alloy (SMA) actuated fluid control valve", International Publication WO 01/33306,10 May 2001

[7] Mohammad Malik, "Book on Pressure Relief Devices (ASME codes for pressure regulating Devices)", Mc-Graw Hills Publications, 2006

[8] Plamen Punov, "Research the fuel injection characteristics of a common-rail solenoid injector", Departement of Combustion Engines, Automobiles and Transport, Technical University, Bulgaria, 2015.

[9] M. V. Talamini, A. C. S. de Araujo, A. P. de Camargo, "Operationa Characterization of Pressure Regulating Valves", The Scientific World Journal, 2018.

[10] V B Bhandari, Design of Machine Elements, Third edition, McGraw Hill Education (India) Pvt Ltd. 2010. ISBN; 978-0-07-068179-8,2010.

[11] Bor Mateusz, Borowczyk Tomasz, Karpiuk Wojciech, Spadło Mikolaj, "Concept of a pump for diesel engines fuel supply using hypocycloid drive", International Automotive Conference, 2018.

[12] E.A. Salykin, V.I. Lipilin, A.A. Skorobogatov, "Method of Fuel Injection in Small Diesel Engines", International Conference on Industrial Engineering, 2017.

[13] T K S Sai Krishna, Kasanagottu Shouri, Repala Deepak Kumar, "Design and Analysis of Electronic Fuel Injector of Diesel Engine", International Journal of Scientific \& Engineering Research, Volume 4, Issue 10, October-2013

APPENDIX

Table1: Pugh Matrix for Concept Selection:

\begin{tabular}{|c|c|c|c|c|c|c|c|c|}
\hline PRV & & & & & & & & \\
\hline & \multicolumn{8}{|l|}{ Concegt } \\
\hline Concept & Baseline & 1. cross hole PRV & $\begin{array}{l}2 \text {-magnetic } \\
\text { soienoid }\end{array}$ & $\mid \begin{array}{c}\text { 3-Hydraulc Actuated } \\
\text { Spool Vave }\end{array}$ & $\begin{array}{l}\text { 4-Variable } \\
\text { Orifice PRV }\end{array}$ & 5- ByPass Fluid PRV & 6-SMA & 7- URF Valve \\
\hline & - & $4=$ & $\begin{array}{l}I \\
-\sqrt{2}\end{array}$ & $\prod_{y=}^{\infty}$ & $\sqrt{4}$ & & $=1$ & 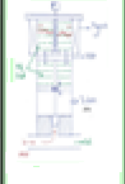 \\
\hline Pressure Control & $\mathrm{s}$ & 5 & 5 & 5 & $s$ & 5 & $s$ & $s$ \\
\hline Leakages & $\mathrm{s}$ & $s$ & + & $s$ & + & $s$ & $s$ & - \\
\hline Structural integrity & $\mathrm{s}$ & + & s & - & - & $s$ & - & - \\
\hline Effect of operating temperature & $\mathrm{s}$ & $s$ & $\mathrm{~s}$ & $s$ & $s$ & $s$ & - & - \\
\hline Ease of manufacturing & $\$$ & + & - & - & - & + & - & - \\
\hline Ease of assembly & $\mathrm{s}$ & + & - & - & 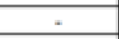 & s & . & 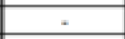 \\
\hline Complexity of design & $s$ & + & - & 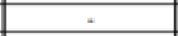 & 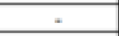 & + & - & . \\
\hline Apprx materialiMFG cost & $s$ & + & . & $=$ & $=$ & + & $=$ & $=$ \\
\hline Packaging & $s$ & $s$ & $s$ & . & $=$ & $s$ & $=$ & $=$ \\
\hline Msturity of Technology Used & $s$ & $s$ & $s$ & $s$ & s & s & s & $s$ \\
\hline Weight & $s$ & $s$ & 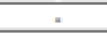 & 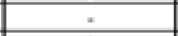 & $=$ & $s$ & $=$ & 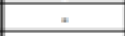 \\
\hline Response Time & $s$ & $s$ & + & $s$ & + & $s$ & + & + \\
\hline & $\mathrm{s}$ & & & & & & & \\
\hline Total E- & 0 & 5 & 2 & 0 & 2 & 3 & 1 & 1 \\
\hline Total I- & 0 & 0 & 5 & 7 & 7 & 0 & 8 & 9 \\
\hline Total 2S S| & 13 & 7 & 5 & 5 & 3 & 9 & 3 & 2 \\
\hline Total & 0 & 5 & 3 & .7 & .5 & 3 & .7 & -8 \\
\hline Rank & 6 & 1 & 5 & 8 & 7 & 2 & 9 & 11 \\
\hline
\end{tabular}




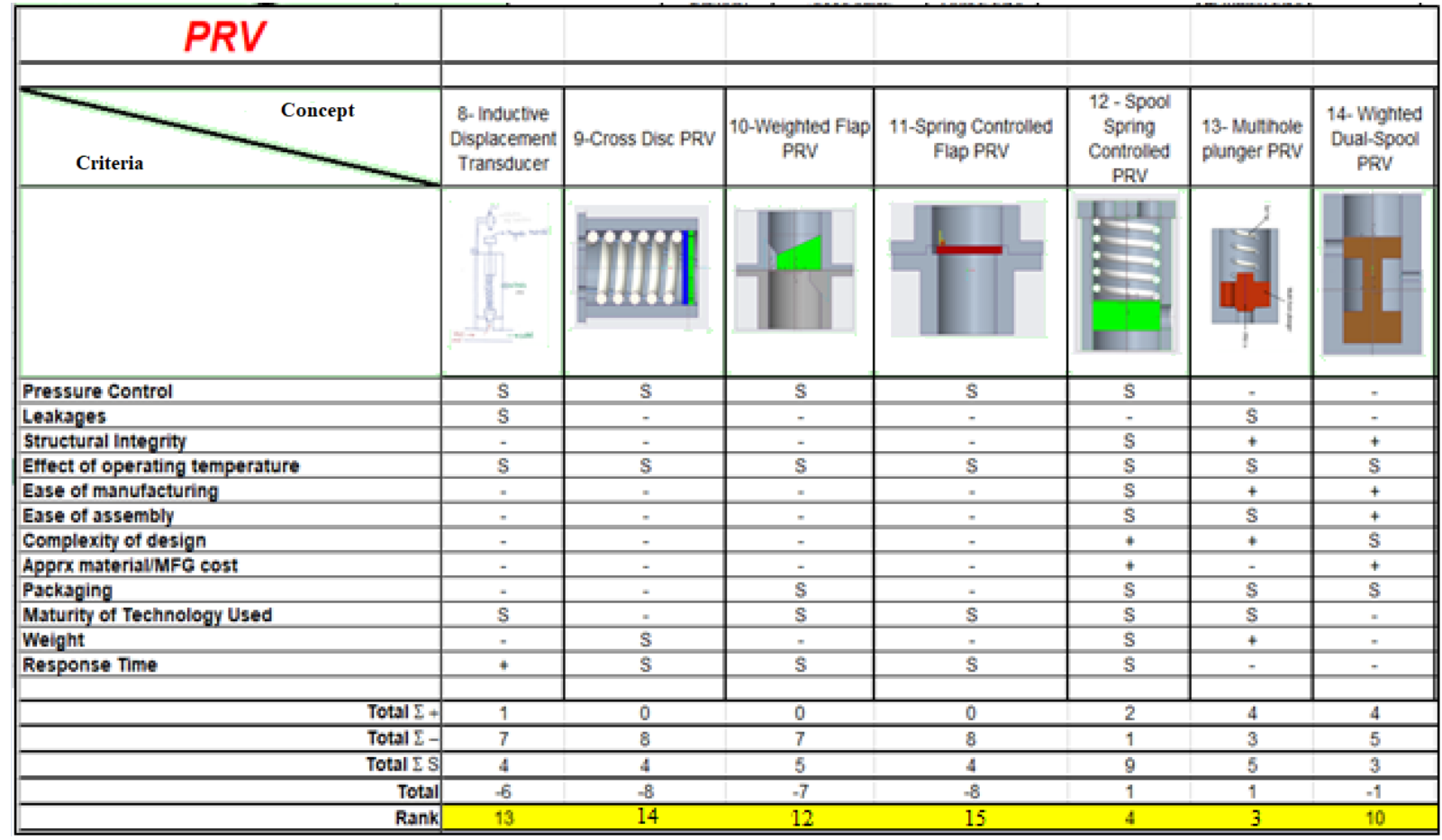

Table 2: Cause and Effect matrix for Concept Selection

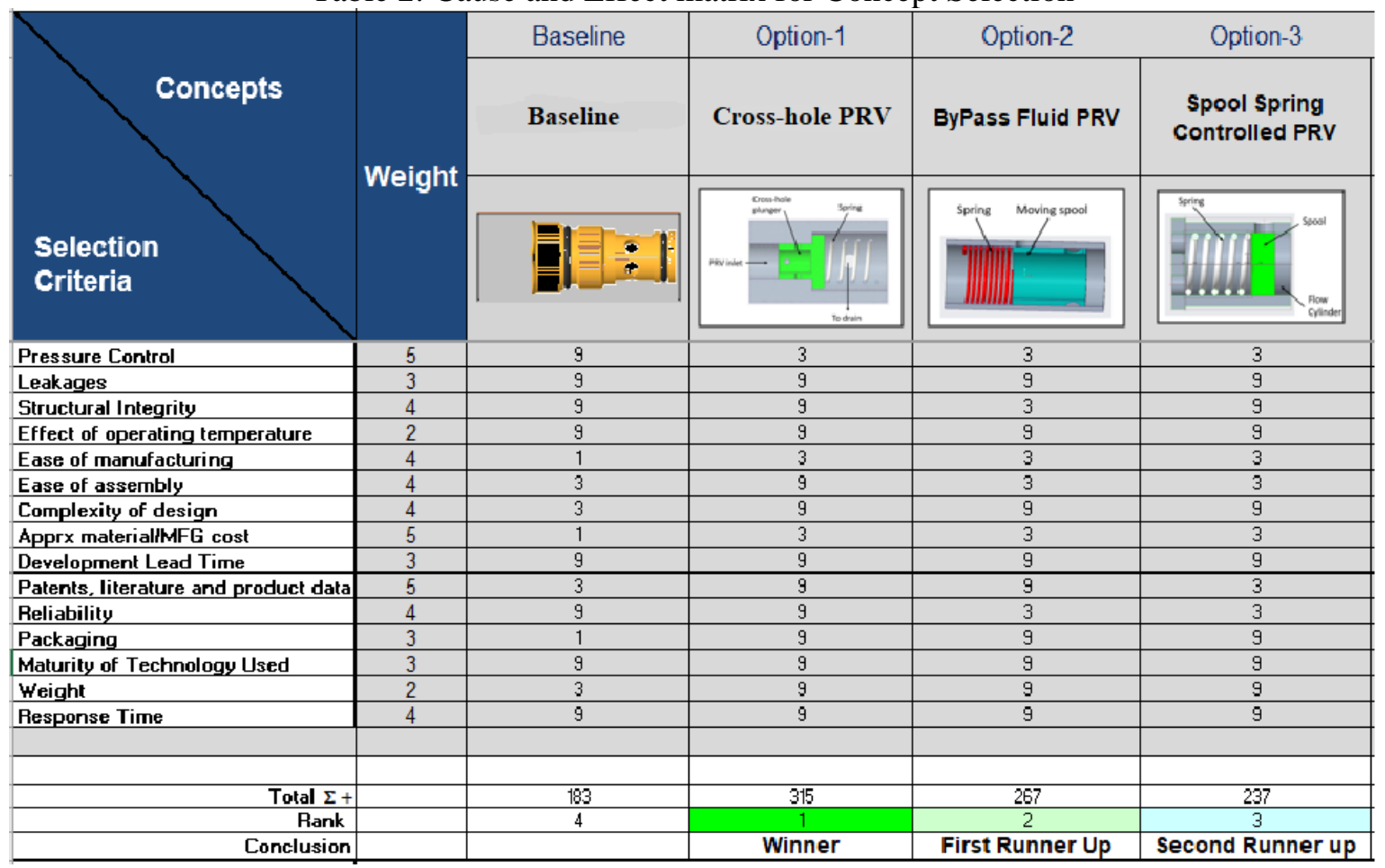

